\title{
The Benefits of Participation in National Service Scheme
}

\author{
Aninha Lobo*
}

\section{Abstract}

The objective of National Service Scheme (NSS) is to increase levels of social consciousness by getting students involved in activities that address individual and community needs. Although there is an incentive, by way of additional marks that students obtain for 120 hours of work, NSS offers opportunities for personal growth, and character development through community service. Participation in NSS activities has instilled in many, the desire to bring about social change. The present study explores the following questions: What motivates NSS participation? What are the goals that are accomplished and motives that are fulfilled through NSS participation? Would involving students in designing, planning and implementing NSS related activities have greater motivational and other benefits? What are the benefits of linking NSS activities and academics? Would student learning be enhanced? Would there be a better assimilation of concepts studied? Would NSS participation provide the base for experiential learning that can be related to concepts discussed in the classroom? Answers to the questions raised above have implications for adapting or extending NSS along the lines of service learning. The integration of experiential education or a practical/applied dimension to theoretical issues addressed in the classroom, would not merely increase interest and understanding but also make students independent learners, and when applied to the

* Department of Psychology, Sophia College for Women, Mumbai 400 026; aninhalobo@gmail.com 
community related issues, help to sensitize and motivate them to contribute to the common good.

Keywords: National Service Scheme; Experiential education; Service learning

\section{Introduction}

National Service Scheme (NSS) provides students with opportunities to engage in activities that address individual and community needs. Although the objective of NSS is personality development through community service, there is little or no research on the motives for participation or goals accomplished through participation in NSS.

Every college student has a unique mix of interests, feelings, and circumstances that leads her or him to join NSS. According to Clary, Snyder, and Stukas (1998) there are six functional motivations for volunteering for community service. These can be measured with the Volunteer Functions Inventory (VFI) developed by them. These include Values Expression, Career, Understanding, Ego Enhancement, Ego Protective and Social Functions. To the extent to which NSS activities involve voluntary participation in serving communities, the same six functional motivations may apply in explaining student participation in NSS activities. The brief description of the functions that motivate participation follows:

i. Values expression function: This is the opportunity to express altruistic or humanitarian concerns for others. Helping other people, especially the less fortunate brings joy.

ii. Career function: This is the opportunity to gain career related experience, develop skills and explore possible career options.

iii. Understanding function: This meets the desire to better understand the social world, obtain new learning experiences and exercise unique skills and abilities. 
iv. Ego enhancement function: This meets the desire to feel better about oneself to feel needed by others; to grow and develop psychologically.

v. Ego protective function: Using one's time, abilities and skills to help the less fortunate helps avoid negative feelings, such as guilt that emanate from not doing anything to alleviate the sufferings of others.

vi. Social function: Working with others for the common good not only helps in meeting expectations and bringing approval, but also helps in forming, building, and keeping relationships.

Adolescence is a time of self-exploration and discovery; a time to develop and hone one's skills. NSS participation provides a diverse range of experiences that go a long way in developing competencies and skills that will help meet life's challenges.

In the context of higher education, NSS has the potential to facilitate learning, by exposing students to real-life issues. By facilitating a reflection on these issues and the search for the roots of these problems and their possible solutions, teachers can trigger critical and creative thinking.

An earlier study conducted by the author in collaboration with the NSS unit of the college provided evidence for the usefulness of experiential exercises in facilitating students' understanding of various concepts, their relevance to daily life and their connection to course work. Prior to the conduct of the main experiment First and Second Year Bachelor of Arts students were trained to conduct experiential exercises (simulations and laboratory games, like Prisoner's Dilemma, Tragedy of the Commons) with other students. As part of the training, they were asked to look for parallels between the exercises and situations in daily life and shown how to facilitate a post-session discussion. This experience was beneficial not only for the student facilitators but also for the student participants. Although many were wary about the use of this methodology with the high school students of the Municipal schools, especially in a post lunch session (given that these students are not accustomed to the use of discussions in developing higher order thinking skills like application and drawing inferences), the 
student facilitator experience was quite to the contrary. These exercises were found to be useful in sensitizing high school and undergraduate college students to the process and benefits of cooperative choices. The post exercise discussion session related the exercises to several issues, namely, conservation and other ecological concerns, interpersonal relationships, group dynamics, the role of communication, trust, mistrust, and betrayal, and the importance of individual action and contribution (no matter how small or inconsequential), in bringing about change at the individual, community, national and international levels. The immediate pre-post difference on a measure of social value orientation (Van Lange, Otten, De Bruin, \& Joireman, 1997) and other follow-up measures 1 month, 3 months and 17 months later, established the effectiveness of these experiential exercises. Student facilitators and participants were able to relate their experience and learning to course work in Standard XI, Social Psychology and Foundation Course. Enjoying the learning experience, they spoke of it as 'thought - provoking, an eye-opener, fun and exciting' (Lobo, 2007).

This prompted the present study, wherein the following research question was examined: What are the motivational goals served by involving students in designing, planning and implementing NSS activities and/or linking them to papers they currently studied?

The following hypotheses were tested: There is a relation between (i) involvement in designing, planning and implementing NSS activities and motivation for NSS participation and (ii) linking of NSS activities to papers currently studied by students and motivation for NSS participation.

\section{Method}

The cooperation of NSS Programme officers or coordinators of 25 units in colleges in South - Central Mumbai was obtained. With their assistance, respondents were contacted. These included current NSS students: First, Second and Third Year Degree College and past NSS students (last three years). This initial work was coordinated by the NSS programme officer and unit of Sophia 
College. Thirteen colleges agreed to participate and were sent the questionnaires.

A survey of the activities of the units was conducted to determine (a) the nature and type of activities offered, similarities and differences in these activities across colleges, activities the students liked and found interesting and reasons for the same, (b) role of participation in personal development and maturity (c) motivation to continue with community service after graduation and reasons for the same (d) the extent to which students were involved in designing, planning and implementing the activities and (e) the extent to which curriculum was integrated into the programme. In the present paper, similarities and differences in these activities across colleges, activities the students liked and found interesting and reasons for the same is not presented or discussed.

Nine colleges responded with completed questionnaires. Out of these, 25 questionnaires that were incomplete were discarded. After discarding the incomplete questionnaires the sample size was 186 , of which 166 were students currently studying in the school and 20 others were students who had passed out from the school.

\section{Measures}

The measures that were used included:

i. Rating scales given to current and past NSS students, wherein they indicated the extent of their involvement in planning, designing and implementing activities as well as the extent of linkage of activities to papers currently studied. The 4 point scales ranged from $1=$ not at all to $4=$ to a very large extent.

ii. The Volunteer Functions Inventory (VFI) was given to ascertain motivation for NSS participation. The VFI has 30 Likert-type items equally divided on the six subscales: values, expression, understanding, social career development ego enhancement, ego protection. The term 'volunteering' was substituted with 'NSS participation.' The following item was added "I could get 10 marks through 120 hours of NSS participation." A 4 point rating scale was 
used ranging from $1=$ not at all important to $4=$ extremely important. Internal consistency has been reported to be good, with test retest correlations over a 4- week interval in the range of .64 to .78. The factor structure of the scales confirmed the distinction between the six scales. Nearly all items loaded unequivocally on their factor.

iii. Open ended questions that were given to better understand student involvement in planning, designing and implementing activities, the extent to which activities were linked to papers currently studied and the outcomes of participation in personal life (development and maturity: socially, emotionally, morally, career, etc.) and to validate participant ratings.

\section{Results and Discussion}

Open ended questions. An analysis of the open ended questions on NSS activities organized in different colleges, indicated that NSS programmes in general involve (i) special camping (10 days every year in an adopted village/slum on specific theme) and (ii) regular activities (community work); 120 hours in a year. The activities included improvement of campuses, tree plantation, constructive work in adopted villages and slums, work in welfare institutions, blood donation, adult and non-formal education, health, nutrition, family welfare, AIDS awareness campaigns, construction of durable assets, sustainable development with emphasis on wasteland development and watershed management. Literacy drives, working with welfare organizations such as old age homes, organising medical and health check-up camps, street plays, public awareness camps related to consumer rights and gender issues were some of the other activities that were undertaken.

Ratings. The means and standard deviations for the relevant variables seen in Table1 indicate that of the six motivators for NSS participation, Understanding (opportunities to enhance understanding of self, inner experiences, outside world and other issues), Values Expression (the desire to express humanitarian and altruistic values), and to a lesser extent the desire to enhance the self, that is Ego Enhancement (increase in self-esteem) were more 
important as motivators for NSS participation than Career, Ego Protective and Social functions; the SD pointing towards greater consistency in response for Values expression and Understanding as motivators than for the others.

What is interesting to note is that the means for Additional Marks and the Social Function, were among the lowest, with slightly greater consistency in response for the Social Function served by NSS participation than for Marks. These differences in sources of motivation can be seen in Figure 1.

Mauchly's test indicated that the assumption of sphericity had been violated, $X^{2}(20)=364.848, p=.0001$, therefore degrees of freedom were corrected using Greenhouse-Geisser estimates of sphericity $(\varepsilon$ $=.55$ ), although uncorrected, the $\mathrm{F}$ value and level of significance for sphericity assumed and Greenhouse-Geisser were the same. The results showed that there was a significant effect of source of motivation for participation in NSS, F $(3.309,612.073)=77.094, p=$ .0001. The only insignificant differences between group means on motivators for NSS participation (Bonferroni $p>.05$ ) were between (i) Understanding and Values Expression (ii) Social and Ego Protective (iii) Social and Marks (iv)Career and Ego Protective (v) Career and Marks and (vi) Ego Protective and Marks. All other differences were statistically significant $(p<.0001)$. These results suggest that Understanding and Values Expression, the prime motivators for NSS participation were equally motivating. These were followed by Ego Enhancement.

Table 1: Descriptive Statistics for the Relevant Variables $(\mathrm{N}=186)$

\begin{tabular}{|l|l|l|}
\hline Variables & Mean & S.D. \\
\hline \hline Involvement in planning, designing, implementing activities & 2.5215 & .8134 \\
\hline \hline Link to papers studied & 2.3710 & .8743 \\
\hline \hline VFI: Understanding & 3.2151 & .5539 \\
\hline \hline VFI: Social & 2.2366 & .8158 \\
\hline \hline VFI: Career & 2.5000 & .7189 \\
\hline \hline VFI: Values & 3.1699 & .5269 \\
\hline \hline VFI: Ego Enhancement & 2.8376 & .6872 \\
\hline \hline VFI: Ego Protective & 2.3828 & .7223 \\
\hline \hline Additional Marks as motivator & 2.2312 & 1.1649 \\
\hline
\end{tabular}






Fig. 1: Mean ratings of the relative importance of the motives

\section{Correlations}

Table 2 presents the correlations between (i) Additional marks from the completion of 120 NSS hours, (ii) Involvement in planning, designing and implementing NSS activities, (iii) Linkages to the papers studied and motivation as measured by the Volunteer Functions Inventory.

Significant positive correlations were obtained between Additional marks from NSS hours and Ego Enhancement $r(184)=.19, \mathrm{p}=.008$ and Career $r(184)=.16, \mathrm{p}=.028$. These results suggest that participants were motivated for the Additional marks because the higher percentage obtained through NSS participation not only raised their self-esteem and made them feel better, but had benefits related to career development.

The correlations between Involvement with designing, planning and implementing NSS activities and four of the six motivations, namely Career $\mathrm{r}(184)=.22, \mathrm{p}=.003$, Social $r(184)=.21, \mathrm{p}=.003)$, 
Understanding $r(184)=.18, \mathrm{p}=.016)$, and Values Expression $r(184)$ $=.17, \mathrm{p}=.018$ ) were found to be statistically significant. Although Career and Social as motivator functions obtained lower mean ratings in terms of relative importance (See Table and Fig. 1), the magnitude of the correlations between Career and Social functions and being Involved in designing, planning and implementing NSS activities was greater than those obtained with Understanding and Values Expression where the mean ratings in terms of importance were higher. The results suggest that working together in designing, planning and implementing various activities helped satisfy the Career and Social motive.

Table 2: Correlation between Motivation for NSS Participation on the Volunteer Functions and Link to Papers Studied $(\mathrm{N}=186)$.

\begin{tabular}{|c|c|c|c|c|c|c|c|}
\hline & $\begin{array}{c}\text { VFI } \\
\text { Under- } \\
\text { standin } \\
\mathrm{g}\end{array}$ & $\begin{array}{c}\text { VFI } \\
\text { Socia } \\
1\end{array}$ & $\begin{array}{c}\text { VFI } \\
\text { Caree } \\
r\end{array}$ & $\begin{array}{c}\text { VFI } \\
\text { Values } \\
\text { Expres } \\
\text { s-ion }\end{array}$ & $\begin{array}{c}\text { VFI } \\
\text { Ego } \\
\text { Enhanc } \\
\text { e-ment }\end{array}$ & $\begin{array}{c}\text { VFI } \\
\text { Ego } \\
\text { Protec } \\
\text { t- ive }\end{array}$ & $\begin{array}{l}\text { Link } \\
\text { to } \\
\text { paper } \\
\text { s } \\
\text { studie } \\
\text { d }\end{array}$ \\
\hline $\begin{array}{l}\text { Additional } \\
\text { Marks }\end{array}$ & $\begin{array}{l}.055 \\
\mathrm{p}= \\
.457 \\
\text { n.s. }\end{array}$ & $\begin{array}{l}.093 \\
\mathrm{p}= \\
.205 \\
\text { n.s. }\end{array}$ & $\begin{array}{c}.161 * \\
\mathrm{p}= \\
.028\end{array}$ & $\begin{array}{l}-.059 \\
\mathrm{p}= \\
.423 \\
\text { n.s. }\end{array}$ & $\begin{array}{c}.193^{* * *} \\
\mathrm{p}= \\
.008\end{array}$ & $\begin{array}{l}.084 \\
\mathrm{p}= \\
.252 \\
\text { n.s. }\end{array}$ & $\begin{array}{l}.0002 \\
\mathrm{p}= \\
.997 \\
\text { n.s. }\end{array}$ \\
\hline $\begin{array}{l}\text { Involvemen } \\
\text { t in } \\
\text { Planning, } \\
\text { designing, } \\
\text { implementi } \\
\text { ng activities }\end{array}$ & $\begin{array}{c}177 * \\
\mathrm{p}= \\
.016\end{array}$ & $\begin{array}{c}.214 * \\
* \\
\mathrm{p}= \\
.003\end{array}$ & $\begin{array}{l}.219 \\
* * \\
\mathrm{p}= \\
.003\end{array}$ & $\begin{array}{l}173^{*} \\
\mathrm{p}= \\
.018\end{array}$ & $\begin{array}{l}.008 \\
\mathrm{p}= \\
.911 \\
\text { n.s. }\end{array}$ & $\begin{array}{l}.085 \\
\mathrm{p}= \\
.247 \\
\text { n.s. }\end{array}$ & $\begin{array}{c}.411 * \\
* \\
\mathrm{p}= \\
.0005\end{array}$ \\
\hline $\begin{array}{ll}\text { Link } & \text { to } \\
\text { papers } & \\
\text { studied } & \end{array}$ & $\begin{array}{c}.167 * \\
\mathrm{p}= \\
.023\end{array}$ & $\begin{array}{c}.408 * \\
* \\
\mathrm{p}= \\
.0005\end{array}$ & $\begin{array}{c}.395^{*} \\
* \\
\mathrm{p}= \\
.0005\end{array}$ & $\begin{array}{l}.217 \\
\mathrm{p}= \\
.003\end{array}$ & $\begin{array}{c}.202^{* *} \\
\mathrm{p}= \\
.006\end{array}$ & $\begin{array}{c}.354 * * \\
\mathrm{p}= \\
.0005\end{array}$ & \\
\hline
\end{tabular}

** Significant at the 0.01 level (2-tailed) *significant at the 0.05 level (2-tailed)

The stronger significant positive correlations (2-tailed) between Linkage to papers and motivations for NSS participation: Social $r$ $(184)=.41, \mathrm{p}=.0005)$, Career $r(184)=.40, \mathrm{p}=.0005)$, Ego Protective $r(184)=.35, \mathrm{p}=.0005)$, Values Expression $r(184)=.22, \mathrm{p}=.003)$, Ego enhancement $(\mathrm{p}=.20, \mathrm{p}=.006)$ and Understanding motivation $r(184)=.17, \mathrm{p}=.023)$ point to the potential of NSS participation for personal goal fulfilment when linked with coursework. Here again, 
working in groups to establish links with coursework, with a focus on potential applications of relevant concepts studied to the tasks and activities, helped in meeting the Social and Career motives. The positive correlation between extent of linkage to coursework and the Ego Protective motive suggests that the more they applied what they had learned in helping others, the more they felt that they were putting their time, abilities and skills to good use in helping the less fortunate and the greater the avoidance of guilt and other negative feelings.

The strong link that some of the teachers of Sociology and Psychology forged with NSS, namely the Municipal School Project and N.G.O. Akanksha activities, involving the students in the planning, designing and executing of the activities of the Municipal School Project would be one of the explanations for the ancillary observation of a significant positive correlation $(r=.41 \mathrm{p}<.0005,2-$ tailed) between Involvement in planning, designing and implementing activities and Link to papers studied.

Open ended questions: Involvement in design, planning and implementation. Involvement ranged from preparing teaching aids and teaching at the Municipal school project to planning, organizing, executing events for college festivals, red ribbon club activities, street plays. Communicating with the teachers and Principals obtaining their cooperation, interacting with BMC officials etc. developing skills in communication, coordination and team work were other activities reported.

Some student responses on involvement as facilitating goal accomplishment were:

Understanding:"I learnt how to interact with different people and implement moral values in life; At NSS, we try our level best to organize events in such a way that there is smooth conduct of events. All of us used to work day in and out to look after every minute detail of the event."

Career: "Yes I would like to be a part of NSS to a large extent because I wish to become a social worker. So if I am a part of NSS it will be like my training course, which will help me in the long run." Another student said, "I want to be in planning because it gives you a great experience and there is a start of future training, 
as if you want to go for professions like in organizing stuff. It gave me broader outlook and made me aware of many career activities."

Values Expression: In one student's words, "Yes, because it is good outlet for people like me, that is, students to reach out to people in need and do something worthwhile. It is also a humbling experience for most of us. Participating in dancing for these underprivileged children helped me become aware of the fact that it doesn't require much effort to bring smiles to children who are same as all." Another said, "It is fun organizing for such events. Makes you feel happy you are doing something good for society. Whole experience on a large scale was extremely satisfying and wholesome as it is for such a positive cause - to help people in need. The feedback and outcome was always positive and thankfully received by others and helped motivate me to take more projects with NSS. I was made aware and helped to spread awareness, which helped me in my India."

Ego Enhancement: “This experience gave me a lot of confidence. It helped me increase my creativity, develop my leadership qualities and gave me confidence in speaking to people. It is not only that we are helping others, but also we are learning so much and indirectly helping ourselves to discover and explore, it helps you to be independent. We create our own status and we feel importance of our own self"

Protective: "I have always seen NSS activities as a stress buster."

Some respondents did not answer the question. However, only one respondent said "I would not like to be as I wouldn't be able to handle."

Open ended questions: Link to course work. For the Science students NSS activities were related to Physics, Chemistry, Mathematics, and Microbiology. NSS activities for the Arts students were linked with Psychology, Sociology, History, English, Foundation Course (FC), and Economics. Students saw the linkage as facilitating an understanding of course work, providing a practical dimension to it, developing an awareness of 'the hard truths of the society they live in', and the development of analytical and critical skills and social sensitivity among other application benefits. 
Students' experience of the linkage: "Chemistry PPT and practical experiment demonstration was very much related to my subject. Food adulteration study is also included in my subject Microbiology. I am studying about cancer. By joining NSS I have learned more." Another student said, "English chapters were linked with my literature subject. Also History matter was linked with what we have learnt in FYJC." "I am managing the water conservation project and my major papers are economics, sociology and psychology. Linked to a great extent as it is related to civic life, our subject (foundation course) and also teaches us how to manage and organize our tasks/activities and take our responsibilities like in economics."One student said, "What I have studied in History, helped me in what I taught at the Municipal camp. "Teaching English and songs to children is related to our study." Another student said, "As I am a management student I have to study about the environment as well. So with the help of NSS we can know much more about the environment."

Benefits of linkage: Some of the student responses to the benefits of linking NSS activities to papers studied: "It helped me understand the subject I was teaching a lot better"; "It helps me to know the value of what I am studying and how others are deprived of it. It reinforces my knowledge and makes me humane. The basic concepts of the topics are clearer." According to one student, "to a large extent due to these linkages I get the practical experience and become aware of things;" "Yes, I like the linkage because it helps me to understand the subject in a practical way.....it gives a practical edge to the syllabus."

Differing opinions: A few of the students however felt differently. Some of them did not see either the linkage nor did they see the value of the linkage. In their words, "I had opted for Economics, Psychology and English Literature. There wasn't a one to one correlation between the syllabi for the subjects I studied. The NSS activities, I guess in a very broad - general manner one could see the connections."

"It is not completely linked but helps understanding the social situation and mental framework of people about the economic status - helps me in sociology, psychology and economics to a small extent." Another student was of the opinion that, "It is linked 
to a small extent, as my papers are psychology and political science so it is totally different. If it would have been sociology it would have been to a large extent."

The quantitative data was by and large, in line with respondents' answers to the open-ended questions.

\section{Discussion}

Although for a group of adolescents and youth one would have thought that the Social function of NSS participation would be the prime motivator, followed by the prospect of career openings or breaks, it appears that what primarily motivated students for NSS participation was (i) the desire to better understand individuals and society, learn more about the world through new and different learning experiences, experiences that would provide the opportunity to exercise unique abilities and skills that often go unused and (ii) the desire to express empathy for the less fortunate through helping them in various ways.

These results show the benefits of NSS linkage to course-work for students. Hence, a suggestion is offered in terms of an adaptation or extension of NSS to service learning. Discussing coursework in relation to real-life problems will promote critical, reflective thought, facilitate personal as well as social transformation, and help in preparing students for responsible citizenship. When students respond to social problems, they begin to see themselves as agents of change.

In experiential learning, experience serves as the base for learning. Experience provides the schemas for the assimilation of new concepts. Students can share their unique experiences in relation to the concepts and principles discussed in class; their own examples being more meaningful, and hence more memorable than any that the teacher might provide. Also, descriptions of experiences can be used as case study material for analytical and reflective discussion in small groups. Final year students can generate research hypotheses based on experience, brain storm data collection methods, and/or apply the theories they are learning to possible interventions. 
The teacher can incorporate student observations into explanations and/or discussion sessions. Learning is more engaging since everyone has something to contribute. When students see coursework shedding light on everyday experiences and real life issues, raising questions, finding solutions, learning is no longer purely academic but meaningful.

The benefits of service learning have been widely reported with high school students and college students. For example, Johnson and Notah (1999) used direct service, indirect service and advocacy projects with eighth graders and found that advocacy projects dealing with hazardous waste disposal facilitated student understanding of scientific concepts. Olson (2011) reports that students from an upper psychology neuropsychology course working in an assisted living facility benefitted in terms of better understanding of course content and skills related to working with people with disabilities.

Service learning has the potential to contribute toward the advancement of democratic citizenship, facilitating "the transition from a personally responsible citizen through a participatory citizen to a justice-oriented citizen," wherein injustice is addressed by questioning and changing established systems and structures (Westheimer \& Kahne, 2004, p. 242).

Rather than seeing themselves as helpless in bringing about change, NSS and its possible extension into service learning provides an opportunity to make a difference both to the provider and recipient of the service.

\section{Limitations}

The limitations of the present study include the convenience sample that was used, which leaves open the possibility that some of the psychosocial gains from NSS activities may have stemmed (at least in part) from participants' predispositions. Among the participants, $53.8 \%$ were from a women's college. Hence gender wise distribution females $=136$, males $=42(8$ not specified) was certainly unequal. Due caution would have to be exercised in generalizing these findings to the entire undergraduate student population as some of the subjects were postgraduate students. 
Further research with a representative sample from the entire undergraduate student population is recommended.

The outcomes in this study were assessed solely through paperand-pencil measures. Behavioural measures would be an interesting addition in future research on this issue.

\section{Conclusion}

NSS participation especially when linked to academic courses provides a rich base of experiences for student learning and classroom discussion. When students understand how their classroom learning relates to issues in daily life, their levels of involvement increase. Many of the students who have actively participated in NSS at Sophia College have gone on to work with NGOs as well as pursue higher education and careers in law, social work, corporate sustainability and social justice, gender and development and policy making.

Volunteer work has been seen to relate to later civic and political participation (Metz \& Youniss, 2005) and student participation in community service has been seen to relate to their grade point averages, educational aspirations and self-esteem (Johnson, Beebe, Mortimer, \& Snyder, 1998). The ultimate aim of higher education is to provide students with skills and knowledge that will help them grow and thrive in meaningful careers, as lifelong learners, independent thinkers with the courage of conviction to initiate change, no matter how small. Participation in NSS and its possible extension to service learning is a means towards that end.

\section{References}

Clary, E. G., Snyder, M., \& Stukas, A. A. (1998).Volunteers' motivations: Findings from a national survey. Washington, DC: Aspen Institute. Retrieved http://www.nonprofitresearch.org/usr_doc/15864.pdf

Furco, A. (1996). Service-learning: A balanced approach to experiential education. In Corporation for National Service (Ed.), Expanding boundaries: Serving and learning, (pp. 2-6). Columbia, MD: Cooperative Education Association.

Johnson, M. K., Beebe, T., Mortimer, J. T., \& Snyder, M. (1998). Volunteerism in adolescence: A process perspective. Journal of 
Research on Adolescence, 8, 309-322. http://dx.doi.org/10.1207/ s15327795jra0803_2

Lobo, A. (2007). Using experiential exercises to sensitize students to cooperative choices for sustainable development. Presented at the International Conference of AIAER (All India Association For Educational Research) on Learner Centred Education for Sustainable Development, October $28^{\text {th }}-30^{\text {th }} 2007$ at Shiksha Bharati B.Ed College, SamoorKhurd, Dt. Una, Himachal Pradesh.

Metz, E. C., \& Youniss, J. (2005). Longitudinal gains in civic development through school-based required service. Political Psychology, 26, 413437.

Van Lange, P.A.M., Otten, W., De Bruin, E.M.N., \& Joireman, J.A. (1997). Development of prosocial, individualistic and competitive orientations: Theory and preliminary evidence. Journal of Personality and Social Psychology, 73, 733-746.http://dx.doi.org/10.1037/00223514.73.4.733

Westheimer, J., \& Kahne, J. (2004).Educating the "good" citizen: Political choices and pedagogical goals.PS: Political Science \& Politics, (pp.241247). PS Online www.apsanet.org

Youniss, J., \& Yates, J. (1997).Community service and social responsibility in youth. Chicago, IL: University of Chicago Press. 